\title{
Detection of PrPres in the Spleen of Hamsters Used as An in Vivo Model for Experimental TSE
}

\author{
M. Puricelli*, F. Servida, G. Carcassola and P. Dall'Ara \\ Department of Veterinary Pathology, Hygiene and Public Health, Section of Microbiology \\ and Immunolog, Faculty of Veterinary Medicine, University of Milan, 20133 Milan, Italy \\ *Correspondence: E-mail: maria.puricelli@unimi.it
}

Puricelli, M., Servida, F., Carcassola, G. and Dall'Ara, P., 2006. Detection of prp ${ }^{\text {res }}$ in the spleen of hamsters used as an in vivo model for experimental TSE. Veterinary Research Communications, 30(Suppl. 1), 261-263

Keywords: hamsters, spleen, Transmissible Spongiform Encephalopathies, Western blotting

Abbreviations: i.p., intraperitoneal; MoAb, monoclonal antibody; TSE, Transmissible Spongiform Encephalopathies

\section{INTRODUCTION}

The pathogenesis of TSE has still not been completely clarified and discussed. In fact, in some animal species, other than neuroinvasion, accumulation of $\mathrm{PrP}^{\mathrm{re}}$ in extraneural tissues has also been found, suggesting the possibility of concomitant lymphoinvasion. In particular, in experimentally infected mice, the lymphoreticular system and the spleen are infected for a long before neuroinvasion. Moreover, infection can be detected in the spleen 1 hour after intraperitoneal infection, suggesting that amplification of the pathogen in the spleen is necessary before neuroinvasion, at least for some scrapie strains (Beringue et al., 2000). In a study on prion diffusion in the hamster model, in animals intraperitoneally (i.p.) infected with the scrapie strain $263 \mathrm{~K}$, it was possible to identify a small amount of PrPres in the spleen of the hamsters. Nevertheless, the concentration of $\operatorname{PrP}^{\text {res }}$ in the spleen showed no correlation with the level of $\mathrm{PrP}^{\mathrm{res}}$ accumulation in any segment of the brain tissue. According to the authors, the spleen appeared to play a potential but non-essential role in pathogenesis after intraperitoneal infection in the hamster model (Baldauf et al., 1997). The aim of this work was to improve and validate an extraction method useful for quantification of the $\mathrm{PrP}^{\mathrm{res}}$ in the spleen of prion-infected hamsters.

\section{MATERIALS AND METHODS}

20 outbreed Syrian Golden hamsters were used. 16 out of the 20 animals were infected i.p. with the scrapie strain $263 \mathrm{~K}$ by injecting $500 \mu$ of brain homogenate containing $10^{5} \mathrm{ID}_{50}$. Four hamsters were sacrificed at 70 days post-infection and the other animals at 1 week after the onset of clinical signs. The PrPres extraction from the spleen of hamsters was performed, both with a method routinely used to confirm the diagnosis of BSE in brain tissues (Schaller et al., 1999) and with a method reported by Wadsworth et al. (2001); the second method 
is based on the ability of sodium phosphotungstic acid (NaPTA), in the presence of $\mathrm{MgCl}_{2}$ and at $\mathrm{pH} 7.4$, to selectively precipitate $\mathrm{PrP}^{\mathrm{res}}$ from extraneural tissues of vCJD patients. All the samples were digested with proteinase $\mathrm{K}$ at the final concentration of $50 \mu \mathrm{g} / \mathrm{ml}$. The extracted prion protein was analysed in Western blotting, using both monoclonal antibody 3F4 (aa. 109-112) and SAF 70 (aa. 142-160).

\section{RESULTS}

The spleen of both the positive animal at the highest point of symptomatology and of the negative ones, extracted and analyzed with the method routinely used for diagnosis in brain tissues, failed to show any band related to the prion. On the contrary, in the spleens of infected animals extracted with NaPTA it was possible to identify a weak signal related to the di-glycosilated band (27-30 kDa), but only after 15 min of radiographic film exposure, suggesting the possibility of a false positive. The same method was applied to the whole spleens of 2 infected animals ( 1 at the terminal stage of the disease and 1 sacrificed 70 days post-infection) and allowed detection of the di-glycosilated band in both samples after 2 min of radiographic film exposure. Interestingly, in the infected animal at the terminal stage the spleen contains a greater quantity of $\mathrm{PrP}^{\mathrm{res}}$ than in the animal sacrificed 70 days post-infection.

Since it has been demonstrated that the hamster spleen can be $\operatorname{PrP}^{\mathrm{res}}$ negative despite the presence of PrPres in the CNS (Baldauf et al., 1997), we also analysed the spleens of 8 animals at the terminal stage of disease at the same time. Furthermore, we used two different monoclonal antibodies (3F4 and SAF 70) to verify the specificity of the reaction.

The spleens were homogenized $(10 \% \mathrm{w} / \mathrm{v})$ in PBS containing $4 \%$ Sarcosyl and then centrifuged at $80 \times g$ for $5 \mathrm{~min}$. $500 \mu \mathrm{l}$ samples of the resultant supernatant were incubated for $10 \mathrm{~min}$ at $37^{\circ} \mathrm{C}$. The samples were then mixed with $50 \mathrm{U} / \mathrm{ml}$ of Benzonase and $1 \mathrm{mM}$ $\mathrm{MgCl}_{2}$ and incubated for $30 \mathrm{~min}$ at $37^{\circ} \mathrm{C}$. NaPTA precipitation was performed by adding $40.65 \mu \mathrm{l}$ of a stock solution containing $4 \% \mathrm{NaPTa}$ and $170 \mathrm{mM} \mathrm{MgCl}_{2}$ at $\mathrm{pH}$ 7.4. Samples were incubated at $37^{\circ} \mathrm{C}$ for $30 \mathrm{~min}$ with constant shaking before centrifugation at $15,800 \times \mathrm{g}$ for $30 \mathrm{~min}$. The supernatant was discarded and the pellet resuspended in $200 \mu \mathrm{l}$ of PBS containing $0.1 \%$ Sarcosyl and supplemented with $50 \mu \mathrm{l}$ of $250 \mathrm{mM}$ EDTA in order to eliminate white precipitates probably consisting of insoluble magnesium salts. Samples were then centrifuged again at $15,800 \times g$ for $15 \mathrm{~min}$. The pellets were resuspended with $50 \mu \mathrm{l}$ of PBS containing $0.1 \%$ Sarcosyl and digested with proteinase $\mathrm{K}$ for 1 hour at $37^{\circ} \mathrm{C}$ with constant shaking; digestion was stopped by the addition of $1 \mu \mathrm{l} 50 \mathrm{mM}$ PMSF. Finally, after an additional centrifugation at $15,800 \times g$ for $15 \mathrm{~min}$, the pellets were resuspended to $20 \mu \mathrm{l}$ final volume with Laemmli buffer, transferred to a $100^{\circ} \mathrm{C}$ heating block for $10 \mathrm{~min}$ and analyzed by Western blotting.

Two blots (4 samples/blot) were prepared: the first was blocked for 1 hour and incubated overnight at room temperature with the MoAb 3F4 diluted 1:25,000. The second blot was blocked overnight at $4{ }^{\circ} \mathrm{C}$ and, after washing, was incubated for 1 hour at room temperature with the MoAb SAF 70 diluted 1:500. After a further incubation for 1 hour at room temperature with the secondary antibody, the reaction was developed with a chemiluminescent substrate (Immun-Star HRP chemiluminescent, Bio-Rad) for 2 min. As shown in Figure 1, 


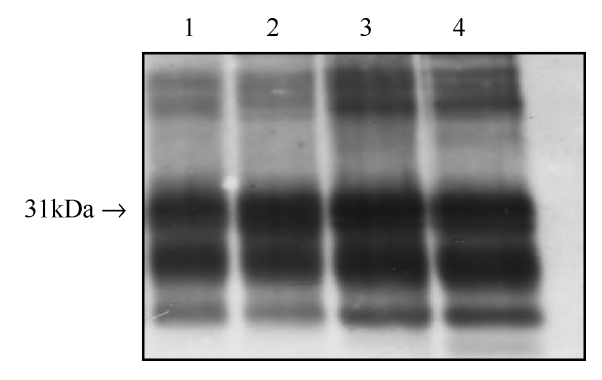

Figure 1. Western blotting detection of $\mathrm{PrP}^{\mathrm{res}}$ in spleens of different i.p. infected hamsters with MoAb SAF 70. Lane 1-4 $\mathrm{PrP}^{\text {res }}$ detected starting from $50 \mathrm{mg}$ of spleen tissue

the reaction with MoAb SAF 70 allowed detection of the $\operatorname{PrP}^{\text {res }}$ band with the expected pattern, quite identical to that obtained when using brain tissues.

\section{DISCUSSION}

In order to detect the presence of $\mathrm{PrP}^{\mathrm{res}}$ in the spleen of infected hamsters, we used a newly developed extraction method, before Western blot analysis, allowing the precipitation of $\mathrm{PrP}^{\mathrm{res}}$. The NaPTA treatment applied before proteolysis causes a change in the PK cleavage site, resulting in the generation of larger $\mathrm{PrP}^{\mathrm{res}}$ fragments, acting on the $\mathrm{N}$-terminal region of $\mathrm{PrP}^{\mathrm{res}}$. By using this procedure, with some modifications, we succeeded in detecting the prion protein in the spleen and obtained the expected bands of prion protein, while in previous reports only very weak signals were obtained. Moreover, it was possible to confirm that the amount of detectable PrPres in the hamster spleen is very low, suggesting that the spleen plays a non-essential role for development of the disease in the hamster experimental model.

\section{REFERENCES}

Beringue, V., Demoy, M., Lasmezas, C.I., Gouritin, B., Wewingarten, C., Deslys, J.P., Andreux, J.P., Couvreur, P. and Dormont, D., 2000. Role of spleen macrophages in the clearance of scrapie agent early in pathogenesis. Journal of Pathology, 190(4), 495-502

Baldauf, E., Beekes, M. and Diringer, H., 1997. Evidence for an alternative direct rout of access for the scrapie agent to brain bypassing the spinal cord. Journal of General Virology, 78, 1187-1197

Schaller, O., Fatzer, R., Stack, M., Clark, J., Cooley, W., Biffiger, K., Egli, S., Doherr, M., Vandevelde, M., Heim,

D., Oesch, B. and Moser, M., 1999. Validation of a western immunoblotting procedure for bovine $\operatorname{PrP}(\mathrm{Sc})$ detection and its use as a rapid surveillance method for the diagnosis of bovine spongiform encephalopathy (BSE). Acta Neuropathologica, 98(5), 437-443.

Wadsworth, J.D.F., Joiner, S., Hill, A.F., Campbell, T.A., Desbruslais, M., Luthert, P.J. and Collinge, J., 2001. Tissue distribution of protease resistant prion protein in variant Creutzfeldt-Jakob disease using a highly sensitive immunoblotting assay. The Lancet, 358, 171-180 